(Paper No. 1988.)

\title{
"On Repairing the Cables of the Allegheny Suspension Bridge at Pittsburgh, Pa., U.S.A."
}

By Francis Collingwood, M. Inst. C.E.

The Author was called upon, in August 1883, to examine the suspension bridge across the Allegheny river at Pittsburgh, and to report upon its condition. The bridge had been in constant use since 1861, having been built by the late Mr. John A. Roebling, well known as a designer of this type of bridge. It consists of two full spans of 343 feet 2 inches length each, and two half-spans of 179 feet 1 inch each. The floor is about 41 feet wide, and is supported on four cables made of iron wire of an average diameter of $0 \cdot 145$ inch. The inner cables are 22 feet between their centres at the lowest point, spreading to 26 feet at the points of suspension. Each cable contains two thousand one hundred wires laid up in seven strands, and measures $7 \frac{1}{2}$ inches in diameter. The outer cables are 42 feet between their centres at the lowest points, reduced to 38 feet at the point of suspension. Each cable contains seven hundred wires laid up in two strands, and is $4 \frac{1}{2}$ inches in diameter. There are heavy iron parapets at the outer sides of the sidewalks, and a system of long stays to each cable, to stiffen the bridge against vertical oscillations. The serving or so-called wrapping-wire on the cables measures 0.098 inch in diameter, and is included, of course, twice in the diameter given for the cables.

The strands pass at the anchorages round a cast-iron shoe, and the shoe is attached by pins to wrought-iron anchor bars. At each end of the small cables there are three, and at each end of the large cables nine, such bars. Those for the large cables are in two sets, so arranged that a rectangle surrounding the strands at the point of attachment is 22 inches square. These bars are the upper set of a series of similar ones, the lowest of which take hold of the anchor-plate, and all the bars and the strands to the clamp to be mentioned were buried in the masonry of the anchorage.

From the shoes the strands converge for about 12 feet, at which point they are brought to a round form and held in close contact by a heavy iron clamp. From thence they are wrapped through- 
out, except where they pass over the saddles at the towers. Between the shoes and the clamp the wires in each strand are brought compactly together by a seizing of several turns of annealed wire at intervals of about every 7 inches. As originally finished, this unwrapped part of the cable was enclosed in heavy cotton duck, and all interior spaces were filled in solid with hot coal-tar, which had been boiled and treated with quick-lime to neutralize any acid it might contain.

As an additional precaution, that portion from the clamp 3 feet back into the masonry was surrounded by $\frac{1}{4}$-inch boiler-plate tightly clamped on, and coal-pitch was poured around the outer end. The whole cable for 12 feet back to and including the shoes was then enclosed in brickwork and cement; 6-inch flags were laid in cement over the brickwork, and finally a second set of flags above these, to form the sidewalk. Over the side cables, the foundations of the tool-houses took the place of the sidewalks.

Examinations had been repeatedly made at the points where the cables emerged from the masonry to see that the coverings were intact, but no more extended examination had been deemed necessary. The Author felt, however, that the responsibility was too grave to allow him to assume that all was sound simply because the exterior appeared so. The sidewalk and flagging: were therefore removed from over one end of a large cable, and on cutting through the canvas it was found that the tar had partially disappeared, and that the cavity was nearly full of a dirty, greyish liquid. There was also extensive rusting of the wires, so that the seizing-wires, 0.06 inch in diameter, were in many places rusted through, and the cable-wires deeply pitted. A second cable-end was opened with similar results. A general survey of the bridge was then made, revealing fine cracks in the paint on the cables which admitted moisture, grave defects in the masonry, particularly of one of the piers, and a number of other minor flaws.

A full statement of the facts was thereupon made to the directors, with the recommendation that every cable should be examined throughout and repairs made immediately; also that the cables and other ironwork should be scraped and repainted, all defective stones in the piers replaced by sound ones, the masonry re-pointed, and that the wrought-iron protecting-plates to the pier nosings should be repaired, \&c.

Authority was given to the Author to proceed with the work at once. As parts of it were entirely novel, it required close personal attention throughout. The first step was to determine how far the damage to the cables extended, One of the openings already 
made was therefore enlarged, and the boiler-plate and wrapping removed, so as to expose the strands back to and around the shoes. It was found that the rust extended outside of the anchorage, and under the wrapping. It was then decided to remove every seizing, to cut out a slit about 45 feet in the bridge floor to where the cable emerged, above it, and to remove the clamp and also the wrapping so far as might be necessary to discover the full extent of the damage. Accordingly, about 10-feet length of cable was unwrapped, leaving the wires exposed and entirely free for about 22 feet of their length.

On examination the serious damage to the wires was found to extend about 3 feet from the anchorage outward. Beyond this there was a little dry rust, but no pitting; and still farther from the anchorage the paint on the interior wires was yet gummy.

The rust seemed to be of two kinds. First, a red oxide, where the wire appeared to have been attacked as if by acid, the socalled fibre being exposed. In some such cases the rust had eaten through the exterior in a narrow slit, and had then attacked the interior, leaving a shell only. The second form of rusting was by the formation of a hard blackish substance containing much sulphur, which, when scaled off, left a deep pit, as if gouged out by a chisel.

In one cable end eight wires had been corroded, and one wire or more in each of the others. Referring to the composition of the rust and the liquid found among the strands, the following letter to the Author is pertinent. The writer, Professor Otto Wuth, is a practical chemist residing in Pittsburgh, and has been engaged in the manufacture of the various products resulting from the distillation of coal-tar.

"PItTSBdrah, Aug. 18th, 1883.

"I have carefully examined the specimens of scales you took from the wires of the cables of the suspension bridge, and found them to be a combination of the hydrated peroxide of iron and sulphate of iron. The liquid consisted of a weak solution of carbonate and sulphate of ammonia, coloured by tarry matter, and is almost identical with tar-water from the gasworks. The cables, as you stated, were first coated with boiled linseed oil and afterwards with coal-tar. The tar had evidently not been heated long enough and high enough to drive off all the water, and the salts of ammonia contained in all coal-tar, at the rate of 5 to 7 per cent.

"The reaction of coal-tar is always alkaline-very alkalinenever acid. The reaction of the acids contained, such as carbolic 
and cresylic, is also alkaline; they do not act like the mineral acids on iron. By heating coal-tar with caustic lime you only convert the carbonate of ammonia into caustic ammonia. Now the action of the coal-tar upon the wires has undoubtedly been this.

"The oils contained in the tar first dissolved the coat of linseed oil; then the sulphuret of ammonia, which is contained in the tar in considerable quantity, acted upon the surface of the iron, converting it into the sulphuret of iron, which again was converted into the sulphate by the oxygen of the air, which could not have been completely excluded. This alternate action of the sulphuret of ammonia and air was continued until the sulphuret was entirely exhausted. The oxidation was further carried on by the atmospheric air in the presence of water and carbonate of ammonia."

How the water came to be where found it is not easy to say. The upper surface of the strands was but 18 inches below the surface of the side-walk, and exposed to considerable alternations of heat and cold. A cavity was evidently formed by the tar gradually oozing into the surrounding brickwork when exposed to the heat of hot summer days. Air would then slowly percolate to and fro as the masonry changed in temperature, and moisture would probably be condensed, and the water slowly collected. It is possible that part of the sulphur and ammonia accumulated in this way, as they must be constantly present more or less in the atmosphere of such a smoky city as Pittsburgh.

It was evident that the only course to pursue was to cleanse the wires thoroughly. This was at first attempted by the use of solvents such as benzole, kerosene, \&c.; but it was impossible to cleanse the interior strands in this way even by drenching them. Scraping each individual wire was then reluctantly resorted to. After trying various scrapers, none of which worked satisfactorily, one was adopted which proved cheap and effective. A $\frac{3}{8}$-inch steel rod had one end flattened and turned up for about $\frac{1}{2}$ inch, so as to make with the rod an angle of about $80^{\circ}$. A semicircular notch, of about the same diameter as the wire, was then filed in the end, and the edge made sharp, hardened, and tempered. With these, four men could clean about one hundred and seventyfive wires in ten hours. To get at the interior strands, wedges were used to force them apart. Whenever a damaged wire was found it was marked by a bit of wire twisted on. All such wires were examined, and if the loss of strength was 10 per cent. or more, it was repaired, otherwise it was passed. It was soon found

[THE INST. C.E. VOL. LXXVI.] 
that the damage was almost entirely confined to the outer two layers of wires in each strand. The seizings around the strands had held the wires so closely in contact that the destructive agent had not penetrated farther.

While this preliminary work was going on, experiments were made to determine the best method of repairing the damaged wires. The only previous work of this kind, so far as known, was that done at Niagara Falls $;^{1}$ where, in making the final splice, the two parts of a wire were kept under strain by a bar having a lover pivoted across each end. The shorter arms of these levers were provided with clamps and thumb-screws for taking hold of the ends of the wire to be joined, and gave a lever-arm of 2 inches. The other arms were 10 inches long. The short leverends having been clamped to the extremities of the cable-wire, one of the long arms was fastened by a wire to some fixed object; to the second long arm a spring balance was attached, and to this a pair of small pulleys and tackle, leading finally to some other fixed object. By this means a definite pull on the balance could be transmitted to the two branches of the cable wire, since the separation of the long arms would draw the short ones towards each other.

The difficulties with this apparatus were, first, that it was not self-contained; secondly, the range of motion being small, it required exact fixing on the wires to ensure the ends being in line when the strain was on; thirdly, the room was insufficient for wrapping the splice.

The Author devised an apparatus as follows : a stiff square bar 2 feet 6 inches long had its sides finished smooth, one end was flattened, and to this end a stiff cross-head about 7 inches Iong was firmly riveted. One end of the cross-head was provided with a clamp and thumb-screw for holding the wire to be spliced. The other end of the cross-bar had a notch for receiving the ring of a heavy spring-balance. A second cross-bar about 11 inches long was fitted with a long socket near its centre, so as to slide freely on the long bar. One end of the sliding-bar had also a clamp and thumb-screw for holding the opposite end of the wire to be spliced. Through the remaining end of the sliding-bar was a hole parallel to the main bar of the machine, through which an eye-bolt passed freely. The eye-bolt had a long thread cut upon it, and carried a hand-wheel with a corresponding internal thread. The hook of the balance passed through the eye of the bolt.

This machine gave plenty of movement for extending the 
balance, and taking up the slack of the wire, and was very convenient in all contracted places.

According to Mr. Roebling's original notes, an abstract only of which was available, the maximum working strain per wire is $267 \mathrm{lbs}$., of which 109 lbs. or 41 per cent., is live load, and $158 \mathrm{lbs}$. or 59 per cent., is dead load. A piece of wire said to be from the original bridge wire was tested, with the undermentioned results: -The stretch in this and the following tests was taken on 1 foot of length by a finely divided vernier gauge, having a multiplying lever, and a second vernier for the finer readings.

Diameter of specimen, $0 \cdot 144$ inch; area, $0 \cdot 16286$ square inch. The readings were uncertain up to $200 \mathrm{lbs}$. strain, owing to inaccuracy in the adjustment of the gauge.

$\begin{array}{ccc}\text { Strain. } & \text { Gauge reading. } & \text { Difference. } \\ \overline{\text { Lbs. }} & \overline{\text { Foot. }} & \overline{\text { Foot. }} \\ 200 & 1 \cdot 00017 & 0 \cdot 00023 \\ 300 & 1 \cdot 00040 & 0 \cdot 00024 \\ 400 & 1 \cdot 00064 & 0 \cdot 00023 \\ 500 & 1 \cdot 00087 & 0 \cdot 00022 \\ 600 & 1 \cdot 00109 & 0 \cdot 00022 \\ 700 & 1 \cdot 00131 & 0 \cdot 00020 \\ 800 & 1 \cdot 00151 & 0 \cdot 00033 \\ 900 & 1 \cdot 00184 & \end{array}$

At 1,260 lbs. the wire broke with a measured set of 0.013 foot. Diameter at point of rupture, $0 \cdot 110$ inch ; strength per square inch of full section, 77,365 lbs.

A new splice in a wire when tested gave, under a strain of $\mathbf{3 0 0}$ lbs., an addition of 0.018 inch in length by slip and stretch. Now in splicing in a new piece of wire, the final splice must evidently be made under an excess of strain sufficient to compensate for three things; first, for the probable slip in the splice in taking up a working strain; secondly, for the stretch that will occur in the part (about 2 feet long) contained in the machine while splicing, when it comes under strain; and thirdly, for the extra strain induced by pulling the wire out from a straight line while splicing.

To determine this excess of strain the following calculations were made :-

The slip at the splice is, say . . . . . . . 0.0180

Taking $200 \mathrm{lbs}$. as the average strain in a wire wilh the bridge in use, and 0.00023 foot as the stretch per $100 \mathrm{lbs}$., the 2-feet length of wire in the machine 0.0110 will stretch 0.00023 foot $\times \frac{200}{100} \times 2$ feet $\times 12=$. . .

Suppose the wire in splicing to be drawn 4 inches from a) straight line at the centre of 20 feet in length, the 0.1332

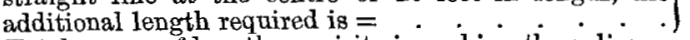
Total excess of length requisite in making the splice $=\overrightarrow{0.1622}$ 
On the supposition that the wrapping around the cables is tight enough to oblige the first 10 feet length under the wrapping to take up the extra strain, and inasmuch as the wires pass around the shoes and have therefore a double length, the stran would act on 60-feet length of wire. According to the previous test, to stretch 60 feet of wire 0.1622 inch a strain would be required equal to

$$
\frac{0 \cdot 1622 \mathrm{inch}}{12} \div \frac{0 \cdot 00023 \text { foot } \times 60 \text { feet }}{100}=98 \mathrm{lbs} .
$$

This would give the strain on the balance as $200+98$, or, say, 300 lbs.

A balance with 400 lbs. capacity was therefore provided, but on trial it was found that a pull of about 500 lbs. was necessary to ensure a full strain in the wire after completion of the splice. The reasons for this seemed to be, first, that the stretch did not probably reach so far as 10 feet under the wrapping; secondly, the friction in passing around the shoe had not been taken into account; thirdly, the wires were frequently partially bound by other wires, and the final splice was nearer one end of the free wire than 10 feet.

Another element of uncertainty was the constantly varying load, as the traffic on the bridge is very heary and subject to rapid and extreme fluctuations. Still another practical difficulty was the fact that from loosening the strands and removing the clamps and wrappings, the angle made by the unwrapped strand, with the round cable was removed 10 feet farther from the shoess and the several cable-wires were no longer equally strained.

For these various reasons it became necessary to assume limits of strain, within which differences would be allowed. As the limit of elasticity of the wire was from 800 to $1,000 \mathrm{lbs}$, and the extreme working-strain $267 \mathrm{lbs}$, it was evident that if the minimum strain per wire was sufficient, the maximum might be largely increased without danger of rupture or inharmonious working. Furthermore, any excess in pull in the sound new wires would tend to relieve the slightly damaged wires which were not to be repaired. This reasoning of course would not apply except to a short length of cable, since an excess of strain introduced into a large number of wires for a considerable length would have changed the curve assumed by the cable.

The minimum fixed upon was 200 lbs. per wire, and was ensured in the following manner. Each wire as spliced was marked by a tag, and once a day all the wires were tested, by applying a 
spring-balance at the centre of their free length, and pulling them out 2 inches from a straight line. Suppose the balance to then mark 8 lbs., by the parallelogram of forces the proportion

$$
\frac{4}{12} \text { inch : } 10 \text { feet }=8 \mathrm{lbs} .: 240 \mathrm{lbs} .=\text { strain of wire. }
$$

This simple test saved all necessity for immediate inspection of each splice.

Two men could repair from eight to ten wires daily, making two splices in each. They soon found that they were able to dispense with the weighing apparatus, and to judge the tension closely enough by feeling.

A simpler tool was then constructed for holding the wire while splicing. It was made of two bars or legs hinged together, and each bent so as to assume a form much like a pair of pin-dividers when they are opened wide, and the pin and point are in position for use. A tightening-rod, with a head at one end and a thumbscrew on the other, passed through the legs at the knuckles. The lower end of each leg was grooved across on one side; and a wedge-key fitted for clamping an end of the wire to be spliced. Most of the splicing was done with this tool; but the one with the balance was best where the space was contracted.

The total number of wires spliced was four-hundred and eightyfour, of which one-hundred and seventy-five were in one cable and one-hundred and seven in another. Care was taken to distribute the splices lengthwise, so as not to interfere with the smooth wrapping of the cable. The splices were made by filing the end of the wire to a flat sloping face of 3 -inches length, and so as to reduce the wire at the extremity to about one-third its diameter. The wire was then laid face downwards on an iron anvil, and the convex side nicked for $3 \frac{1}{2}$ inches with a tool, having spaces of 0.033 inch to correspond with the diameter of the splicing wire.

After preparing the two ends, they were placed in the machine, the proper strain was applied, and the flat surfaces were brought in contact and tightly clamped by a hand-vice on each side of the centre of the splice.

The splicing-wire was next tightly wrapped by hand; beginning at the middle of both splice and wrapping-wire, and wrapping up to one of the hand-vices, then removing this vice to a second and third hold and each time wrapping up to it. The final finish at this end was given by wrapping $\frac{3}{4}$ inch beyond the filed portion of the wire, and fastening the splicing-wire by passing it twice under its own coils. The opposite half splice was finished in the same manner. 
The integrity of the splice depends upon the care taken in adjusting the parts accurately to each other, and keeping a constant strain on the splicing-wire.

Comparative tests were made of a piece of wire from one of the cables, and of a new splice in the same, and the results are given below.

Diameter of wire $=0.144$ inch, area $=0.16286$ square inch. The whole wire behaved as follows :-

$\begin{array}{ccc}\text { Strain. } & \text { Gauge-reading. } & \text { Difference. } \\ \overline{\text { Lbs. }} & \overline{\text { Foot. }} & \overline{\text { Foot. }} \\ 200 & 1 \cdot 000050 & 0 \cdot 000240 \\ 300 & 1 \cdot 000290 & 0 \cdot 000245 \\ 400 & 1 \cdot 000535 & 0 \cdot 000250 \\ 500 & 1 \cdot 000785 & 0 \cdot 000210 \\ 600 & 1 \cdot 000995 & 0 \cdot 000270 \\ 700 & 1 \cdot 001265 & 0 \cdot 000275 \\ 800 & 1 \cdot 001540 & \end{array}$

At 1,450 lbs. the wire broke with a set of 0.0208 foot on 1 foot. The reduction of area at the point of rupture was 51 per cent. The strength per square inch was 89,015 lbs.

The splice from the same piece of wire gave results as follows :-

$\begin{array}{ccc}\text { Strain. } & \text { Gauge-reading. } & \text { Difference. } \\ \overline{\text { Lbs. }} & \overline{\text { Foot. }} & \overline{\text { Foot. }} \\ 100 & 1 \cdot 000390 & 0 \cdot 000225 \\ 200 & 1 \cdot 000615 & 0 \cdot 000665 \\ 300 & 1 \cdot 001280 & 0 \cdot 000505 \\ 400 & 1 \cdot 001785 & 0 \cdot 000550 \\ 500 & 1 \cdot 002335 & 0 \cdot 000405 \\ 600 & 1 \cdot 002740 & 0 \cdot 000450 \\ 700 & 1 \cdot 003190 & 0 \cdot 000285 \\ 800 & 1 \cdot 003475 & 0 \cdot 000180 \\ 900 & 1 \cdot 003655 & \end{array}$

At 1,350 lbs. the spliced wire broke with a set of 0.0243 foot on 1 foot. The rupture occurred in one wire at $2 \frac{1}{2}$ inches from the end, or 1 inch from the centre of the splice, and with a large local reduction in area. In making the test the coils of wrapping-wire were left slightly loose at the ends to represent a probable case in actual work.

In comparison with the uncut wire, the splice shows a strength of 93 per cent. Since the splice at one end of each piece of new wire introduced has been subjocted to a strain far above the working-strain, and the final splice has resisted a pull of at least $200 \mathrm{lbs}$, it is evident that the greatest possible additional slip would be that arising from the slip at the final splice, due to the 
difference between a strain of $200 \mathrm{lbs}$. and a maximum strain of 267 lbs. As this amount, which is very small, must be distributed over 60 feet length of wire it may be neglected.

A piece of new Bessemer-steel wire was tested with the following results :-

Diameter of wire $=0.147 \mathrm{inch}$, area $=0.01697$ square inch.

$\begin{array}{ccc}\text { Strain. } & \text { Gauge-reading. } & \text { Difference. } \\ \overline{\text { Lbs. }} & \overline{\text { Foot. }} & \overline{\text { Foot. }} \\ 300 & 1 \cdot 000725 & 0 \cdot 000200 \\ 400 & 1 \cdot 000925 & 0 \cdot 000230 \\ 500 & 1 \cdot 001155 & 0 \cdot 000345 \\ 600 & 1 \cdot 001500 & 0 \cdot 000125 \\ 700 & 1 \cdot 001625 & 0 \cdot 000230 \\ 800 & 1 \cdot 001855 & 0 \cdot 000280 \\ 900 & 1 \cdot 002135 & 0 \cdot 000270 \\ 1,000 & 1 \cdot 002405 & 0 \cdot 000335 \\ 1,100 & 1 \cdot 002740 & 0 \cdot 000405 \\ 1,200 & 1 \cdot 003145 & \end{array}$

At 1,550 lbs. the Bessemer-steel wire broke with a set of 0.0243 foot on 1 foot. The reduction of area at the point of rupture was $47 \frac{1}{2}$ per cent. The strength per square inch was 90,442 lbs.

The tensile-strength of similar sized iron-wire is given by tho Trenton Iron Co. at 91,278 lbs. per square inch.

Considering that the old wire was more or less damaged by rust, its uniformity of stretch, large reduction, and close approximation in strength, shows it to be entirely unchanged by use.

All the wires in a cable having been repaired, the first step towards closing it up was to jar it thoroughly with mallets, and to get out all loose rust and dirt, after which it was thoroughly saturated with raw linseed oil. To reach the interior wires with the oil, a chisel bar had to be forced through in every direction until no uncoated wire could be found. Two days afterward a coating of boiled linseed oil was applied, and then the seizings were replaced on the part of the strands not to be wrapped. The most serviceable tool for compacting the wires of a strand to a round form, prior to replacing the seizings, was one devised for the occasion. It consisted of two semicircular pieces of iron hinged together at one end of each, and with the free ends bent radially outward. One of the free ends was left longer than the other, and had a hole slotted radially in it, to allow play for the passage of the screw. The other free end was tapped for the screw. The screw had a thread about 4 inches long, and a stem about 1 foot long terminating in a $T$ for convenience in turning. A collar 
between the screw and stem gave a bearing against the slotted end of the clamp. The interior strands, which were hard to get at, were compacted with this clamp with facility.

The work of bringing the strands together again to the round form of the cable, just within the anchorage, was troublesome but not new. The wrapping of that portion outside the anchorage was at first accomplished with the special wrapping-machines used when the bridge was built. As it was impossible to employ these at all points, the ordinary serving mallet familiar to sailors was afterwards adopted, as with care it was found that good work could be effected.

The cable was saturated with white lead and oil in advance of the wrapping. Several coats of the same composition were afterwards applied over the wrapping and strands. Wherever direct vision could not be obtained, the aid of a mirror was found necessary to ensure a perfect covering.

As it would afterwards have been difficult to paint thoroughly that portion of the cable where the strands converge to a round form, it was considered best to protect it by filling for a space of 2 feet back from the clamp with paraffin. To do this a dam of putty was made across the cable, and the 2 -feet length was surrounded by canvas, into which melted paraffin was poured until when cold the canvas would hold no more. Changes of temperature have thus far had no effect upon the paraffin as a protection.

Experience having demonstrated the imperative necessity of having all parts of the cable accessible for examination, it was decided to leave tunnel-openings around the strands in the anchorages. The bottom of each opening in the masonry was therefore cut so as to drain to an opening in the front wall. The sides were removed to about 6 feet by 16 feet, and lined with 13-inch brick walls laid in cement-mortar, the cable passing freely through the front wall, with space all around for painting. A jacket was afterwards put on each cable to keep out moisture as far as practicable. As the head-room was insufficient for brick arches, the side walls were capped by an iron box-frame, which was covered by a series of cast-iron plates grated on the upper surface, which surface was at the side-walk grade. The plates were locked together and cemented, to prevent water from dropping on the cables; and the last plate of the series was provided with lifting rings.

In the alternation of mild and extreme cold weather, water of condensation was found to drip from the plates; to prevent this a light wooden frame has been covered with well-painted 
Papers.] Collingwoon on Repairing a suspension BRIDGe. 345

canvas and placed in the tunnel in an inclined position over the cable. Cork paint may be hereafter applied to the interior of the tunnels.

The only other point of interest was the method pursued in removing the old paint from the cables preparatory to repainting. The necessity of this was made apparent by the cracks retaining moisture after every shower; as it was reasoned that fresh paint would soon crack in the same lines, and but temporarily cure the evil. Ordinary scrapers were first tried, but were ineffective on account of the gumminess of the paint. This led to the use of cutting-tools such as chisels and drawing-knives, by which to slice it off. By keeping these sharp, the work was fully trebled in quantity over that at first attainable. The average length of large cable cleansed by one man in a day was about 25 feet. 